\title{
DIRICHLET BOUNDARY VALUE PROBLEM RELATED TO THE $p(x)$-LAPLACIAN WITH DISCONTINUOUS NONLINEARITY
}

\author{
MUSTAPHA AIT HAMMOU
}

Abstract. In this paper, we prove the existence of a weak solution for the Dirichlet boundary value problem related to the $p(x)$-Laplacian

$$
-\operatorname{div}\left(|\nabla u|^{p(x)-2} \nabla u\right)+u \in-[\underline{g}(x, u), \bar{g}(x, u)],
$$

by using the degree theory after turning the problem into a Hammerstein equation. The right hand side $g$ is a possibly discontinuous function in the second variable satisfying some non-standard growth conditions.

MSC 2010. 47H04, 47H11, 47H30, 35D30, 35J66.

Key words. Set-valued operators, nonlinear elliptic equation, $p(x)$-Laplacian, Sobolev spaces with variable exponent, degree theory.

\section{REFERENCES}

[1] R. Aboulaich, D. Meskine and A. Souissi, New diffusion models in image processing, Comput. Math. Appl., 56 (2008), 874-882.

[2] J. Berkovits, Extension of the Leray-Schauder degree for abstract Hammerstein type mappings, J. Differential Equations, 234 (2007), 289-310.

[3] J. Berkovits and M. Tienari, Topological degree theory for some classes of multis with applications to hyperbolic and elliptic problems involving discontinuous nonlinearities, Dynamic Systems and Applications, 5 (1996), 1-18.

[4] Y. Chen, S. Levine and M. Rao, Variable exponent linear growth functionals in image restoration, SIAM J. Appl. Math., 66 (2006), 1383-1406.

[5] K. C. Chang, The obstade problem and partial differential equations with discontinuons nonlineantres, Comm. Pure Appl. Math., 33 (1980), 117-146.

[6] K. C. Chang, Critical Point Theory and Applications, Shanghai Scientific and Technology Press, Shanghai, 1986.

[7] X. L. Fan and D. Zhao, On the spaces $L^{p(x)}(\Omega)$ and $W^{m, p(x)}(\Omega)$, J. Math. Anal. Appl., 263 (2001), 424-446.

[8] I. S. Kim, A topological degree and applications to elliptic problems with discontinuous nonlinearity, J. Nonlinear Sci. Appl., 10 (2017), 612-624.

[9] P. Harjulehto, P. Hästö, M. Koskenoja and S. Varonen, The Dirichlet energy integral and variable exponent Sobolev spaces with zero boundary values, Potential Anal., 25 (2006), 205-222.

[10] O. Kováčik and J. Rákosník, On spaces $L^{p(x)}$ and $W^{1, p(x)}$, Czechoslovak Math. J., 41 (1991), 592-618.

The author thanks the referee for his helpful comments and suggestions.

DOI: $10.24193 /$ mathcluj.2021.2.10 
[11] M. Rǔžička, Electrorheological fuids: modeling and mathematical theory, Lecture Notes in Mathematics, Vol. 1748, Springer-Verlag, Berlin, 2000.

[12] S. G. Samko, Density of $C_{0}^{\infty}\left(\mathbb{R}^{N}\right)$ in the generalized Sobolev spaces $W^{m, p(x)}\left(\mathbb{R}^{N}\right)$, Dokl. Akad. Nauk, 369 (1999), 451-454.

[13] D. Zhao, W. J. Qiang and X. L. Fan, On generalizerd Orlicz spaces $L^{p(x)}(\Omega)$, Journal of Gansu Sciences, 9 (1996), 1-7.

[14] Z. Zeidler, Nonlinear functional analysis and its applications, II/B: Nonlinear monotone operators, Springer-Verlag, New York, 1985.

Received January 23, 2020

Accepted February 11, 2021
Sidi Mohamed Ben Abdellah University

Faculty of Sciences Dhar El Mehraz

Laboratory LAMA, Department of Mathematics

Fez, Morocco

E-mail: mustapha.aithammou@usmba.ac.ma

https: //orcid.org/0000-0002-3930-3469 